\title{
A CONSTRUÇÃO DO FEMININO E DO MASCULINO NO PROCESSO DE CUIDAR CRIANÇAS EM PRÉ-ESCOLAS ${ }^{1}$ \\ THE CONSTRUCTION OF THE FEMININE AND OF THE MASCULINE IN THE PROCESS OF TAKING CARE OF CHILDREN IN PRE-SCHOOLS \\ LA CONSTRUCCIÓN DE GÉNERO FEMENINO Y MASCULINO EN EL PROCESO DEL CUIDAR A LOS NIÑOS EN LOS JARDINES MATERNALES
}

\author{
Vera Lúcia de Oliveira Gomes²
}

\begin{abstract}
${ }^{1}$ Apoio: Fundação de Amparo à Pesquisa do Estado do Rio Grande do Sul (FAPERGS) e Conselho Nacional de Pesquisa (CNPq).
${ }^{2}$ Enfermeira. Doutora em Enfermagem pela Universidade Federal de Santa Catarina (UFSC). Professora Titular do Departamento de Enfermagem da Fundação Universidade Federal do Rio Grande (FURG). Líder do Grupo de Estudos e Pesquisas sobre Enfermagem, Gênero e Sociedade (GEPEGS).
\end{abstract}

PALAVRAS-CHAVE: Cuidado da criança. Identidade de gênero. Educação infantil.

PALABRAS CLAVE: Cuidado del niño. Identidad de género. Crianza del niño.

KEYWORDS: Child care. Gender identity. Child rearing.

RESUMO: Objetivou-se investigar como se constrói o feminino e o masculino no processo de cuidar crianças em uma pré-escola do município de Rio Grande - RS. Adotou-se a hermenêutica dialética e a concepção de habitus de Bourdieu como referenciais metodológico e teórico-filosófico, respectivamente. Utilizou-se, para coleta de dados, a observação registrada em diário de campo e entrevista semiestruturada com as cuidadoras, pois são elas que mais interagem com as crianças. Respeitaram-se os princípios éticos constantes da Resolução 196/96. Pela análise de conteúdo, apreendeu-se que as cuidadoras são solícitas, atenciosas e carinhosas com todas as crianças. No entanto, cuidam, de forma natural e culturalmente diferenciada, meninos e meninas. Àqueles permitem brincadeiras mais arriscadas, inovadoras, espetaculares, enquanto que as meninas devem seguir a norma do jogo. Nos primeiros anos, as crianças já têm interiorizado um padrão de comportamento típico de cada sexo tendo dificuldade, pela própria pressão do grupo, em transgredi-lo.
ABSTRACT: This study aimed to investigate how the feminine and the masculine in the process of taking care children in a preschool of Rio Grande - RS are created. The sense interpretation according to the old philosophy, and the conception of habitus of Bourdieu as methodological and theoretical- philosophical references, respectively were adopted. Data was collected through daily observation registered in field and semi-structured interviews with the caretakers, as they are those who most interact with the children. The ethical principles of Resolution 196/96 were respected. For the content analysis, it was learned that the caretakers are solicitous, kind and affectionate with every child. However, they take care in a natural way and thus culturally differentiated between boys and girls. Boys were allowed riskier, innovative, and spectacular games, while the girls were made to follow the rules of the games. In the first years, the children have already been internalizing a pattern of typical behavior of each sex finding difficulty in transgressing it, due to pressure from the group itself.

RESUMEN: El objetivo fue investigar como se construye el femenino y el masculino en el proceso del cuidar a los niños en una educación parvularia de Río Grande - RS. Se adoptó la hermenéutica dialéctica y la concepción de habitus de Bourdieu como referenciales teórico-filosófico y metodológico respectivamente. Fue usado, para la recolección de datos, la observación, que se registró en el diario de campo y entrevistas semi estructuradas con las acompañantes, porque son las que más interactuan con los niños. Se respetaron los principios éticos constantes de la Resolución 196/96. Por el análisis de las informaciones, se aprendió que las acompañantes son solícitas, cordiales y afectuosas con todos los niños. Sin embargo, cuidan de manera natural y culturalmente diferenciada niños y niñas. Estas permiten a los niños, los juegos más arriesgados, innovadores y espectaculares, mientras que las niñas deben seguir la norma del juego. En los primeros años, los niños ya han internalizado un modelo de conducta típico de cada sexo, teniendo dificultad debido a la propia presión del grupo en infringirla.

Endereço: Vera Lúcia de Oliveira Gomes. Av. Presidente Vargas, 602, Bl. 1, Ap.401 96.202-100 - Vila Junção, Rio Grande, RS. E-mail: vlogomes@terra.com.br
Artigo original: Pesquisa Recebido em: 13 de agosto de 2005 Aprovação final: 23 de fevereiro de 2006

Texto Contexto Enferm, Florianópolis, 2006; 15(1): 35-42. 


\section{INTRODUÇÃO E JUSTIFICATIVA}

Atualmente, é inegável que os primeiros anos de vida constituem o alicerce para o harmonioso crescimento e desenvolvimento do indivíduo. O projeto "Começando melhor", elaborado pelo Comitê de Desenvolvimento Integral da Primeira Infância (CODIPI), fundamenta-se referindo que, nesse período, "experiências e interações com os pais, os membros da família e outros adultos influenciam a maneira como a mente de uma criança se desenvolve com o impacto tão grande quanto o de fatores como nutrição adequada, boa saúde e água limpa". 1:4 Assim, fica evidente que, ao final da primeira infância, o cérebro de uma criança já desenvolveu os amplos contornos de sua auto-estima, de senso de moralidade, responsabilidade e empatia, de aprendizado, de relacionamento social, bem como já interiorizou as crenças e valores culturalmente determinados, entre outros aspectos de sua personalidade.

Em nossa cultura, cuidar crianças é a tarefa tradicionalmente realizada por mulheres em ambiente familiar. No entanto, com sua inserção no mercado de trabalho, a mulher criou a necessidade de estruturação de locais destinados ao cuidado infantil. Assim, os primeiros meses e anos que outrora eram vividos em família hoje transcorrem nas instituições de educação infantil. Conseqüentemente, parte dos ensinamentos que eram ministrados pela família hoje são efetuados por cuidadoras em creches e pré-escolas. Embora, em nosso país, tais instituições sejam numericamente insuficientes, um grande número de crianças nelas permanece a maior parte do período mais fecundo de suas vidas.

A noção de babitus vem sendo usada para referir-se a este aprendizado, que ocorre desde os primeiros momentos de vida e talvez até antes do nascimento. ${ }^{2}$ Dessa forma, a ação de estruturas sociais como a familia, com seus valores e crenças, incidindo sobre o comportamento de crianças, desde a primeira infância, leva, por meio de estratégias sutis e refinadas, a um aprendizado quase natural, ou seja, à incorporação dos habitus primários. Assim, tanto no convívio familiar quanto nas creches e pré-escolas, entre aprovações, censuras, lições de moral, elogios, prêmios e outras modalidades de influências, as crianças vão construindo seus gostos mais íntimos, seus trejeitos, suas aspirações, sua auto-imagem, sua auto-estima, seus estigmas e preconceitos, enfim, vão incorporando os habitus primários que estarão no princípio das experiências escolares. Resumindo, os habitus primários servirão de base à recepção e inculcação da mensagem pedagógi- ca institucional ou escolar. Esta, se incorporada, mesmo que parcialmente, constituirá os babitus secundários, os quais estarão no princípio da percepção e da apreciação das demais experiências do indivíduo. São, portanto, as disposições adquiridas pela experiência de cada agente social ao longo de sua trajetória de vida, que servem de base para suas próprias percepções, apreciações e ações, incluindo aquelas referentes a gênero, credo, raça, classe social, orientação sexual, entre outras. $^{2}$

"A inscrição dos gêneros - feminino e masculino - nos corpos é feita, sempre, no contexto de uma determinada cultura e, portanto, com marcas dessa cultura". 3:11 Nesse sentido, cabe enfatizar que a perpetuação da ordem dos gêneros esteve, até bem pouco tempo, garantida fundamentalmente pela ação conjunta de instituições como a família, a igreja, a escola e o Estado, sobre estruturas inconscientes. ${ }^{4}$ Todavia, é a família que tem o papel mais relevante na reprodução da dominação masculina, pois é no ambiente familiar que a criança, desde a mais tenra idade, vai interiorizando a divisão sexual do trabalho e, conseqüentemente, os estereótipos vão sendo inculcados sob a forma de habitus primários. A Igreja contribui apregoando uma moral antifeminista, fundamentada em valores patriarcais, mas, principalmente, por meio da crença na inata inferioridade feminina. A escola, mesmo libertada da influência da Igreja, colabora com a reprodução de estereótipos ao fundamentar-se na representação patriarcal, que mantém uma estrutura hierárquica com forte conotação sexuada, fazendo do homem o princípio ativo e, da mulher, o passivo. ${ }^{4}$ Ensinamentos contidos nos mais antigos manuais destinados a ensinar mestres a escolarizarem os corpos das crianças evidenciam como era produzida a distinção entre meninos e meninas. "As escolas femininas dedicavam intensas e repetidas horas ao treino das habilidades manuais de suas alunas produzindo jovens 'prendadas', capazes dos mais delicados e complexos trabalhos de agulha ou de pintura. As marcas da escolarização se inscreviam, assim, nos corpos dos sujeitos. Por vezes isso se fazia de formas tão densas e particulares que permitia - a partir de mínimos traços, de pequenos indícios, de um jeito de andar ou falar dizer, quase com segurança, que determinada jovem foi normalista, que um rapaz cursou o colégio militar ou que um outro estudou num seminário", 5:62

No que se refere ao Estado, seu papel na perpetuação dos gêneros consiste em ratificar e até mesmo reforçar as prescrições e proscrições do patriarcado privado com as de um patriarcado público. ${ }^{4}$ Dessas 
quatro instituições, muitos resquícios permaneceram imutáveis em relação à condição da mulher na sociedade, pois se incorporaram sob a forma de habitus, produzindo e reproduzindo práticas opressivas ou potencialmente opressivas. Um dos fatores que, sem dúvida, dificulta o estabelecimento de uma nova ordem é a naturalização da diferença entre homens e mulheres. Por meio de processos culturais, "definimos o que é ou não - natural; produzimos e transformamos a natureza e a biologia e, conseqüentemente as tornamos históricas", 3:11

Quando falamos de gênero, não estamos querendo negar a biologia, mas, sim, destacar o aspecto sociocultural de sua construção. Nesse sentido, "as aparências biológicas e os efeitos, bem reais, que um longo trabalho coletivo de socialização do biológico e de biologização do social produziu nos corpos e nas mentes conjugam-se para inverter a relação entre as causas e os efeitos e fazer ver uma construção social naturalizada (os 'gêneros' como habitus sexuados), como o fundamento in natura da arbitrária divisão que está no princípio não só da realidade como também da representação da realidade e que se impõe por vezes à própria pesquisa" 4:9-10

Essa estrutura social naturalizada induz a uma enormidade de ações e decisões inquestionáveis. Assim, cabe à mulher o cuidado dos filhos, do marido, e todas as atividades por vezes invisíveis realizadas no âmbito privado, já ao homem são atribuídas aquelas tarefas perigosas ou espetaculares do espaço público. Dessa forma, o espaço de lutas vai muito além do âmbito doméstico, há sempre uma mão direita e uma mão esquerda no Estado. "A mão direita do Estado é a das finanças, do orçamento, tudo o que é soberano, tudo o que é masculino; a mão esquerda, tudo o que é feminino: hospitais, creches, escola" $6: 50$

Outra face da divisão sexual do trabalho referese ao fato de que uma mesma tarefa pode conferir grande prestígio quando executada por homem, e ser considerada elementar ou fútil quando executada por mulher. A diferença entre um cozinheiro e uma cozinheira e entre um costureiro e uma costureira podem ilustrar esse estereótipo. ${ }^{4}$

Referindo-se a essa ordem natural, na perspectiva bourdiesiana, "cada vez que se diz é natural, há manipulação, dominação. O discurso dominante naturaliza as coisas como elas são. Diz-se: é deste jeito, sempre foi deste jeito" ${ }^{6: 50}$ Nesse sentido, clássicas definições de gênero podem subsidiar reflexões acerca da naturalização/desnaturalização das diferenças entre homens e mulheres. Assim, “[...] o gênero é um elemento constitutivo de relações sociais fundadas sobre as diferenças percebidas entre os sexos, e o gênero é um primeiro modo de dar significado às relações de poder". 7:14 Daí apreende-se que "ser mulher não é apenas diferente de ser homem, como também implica inferioridade, desvalorização, opressão". 8:277 Essas são algumas das contribuições de estudiosas feministas da década de noventa, que muito têm auxiliado para desnaturalizar as diferenças entre os sexos e incitar a realização de estudos que possibilitem a compreensão de tais diferenças como decorrentes de uma construção social, na qual o processo educativo, formal ou informal, exerce papel preponderante.

$\mathrm{Na}$ realidade, "as divisões constitutivas da ordem social e, mais precisamente, as relações sociais de dominação e de exploração que estão instituídas entre os gêneros se inscrevem, assim, progressivamente entre duas classes de habitus diferentes, sob forma de hexis corporais opostos e complementares e de princípios de visão e de divisão, que levam a classificar todas as coisas do mundo e todas as práticas segundo distinções redutíveis à oposição entre o masculino e o feminino". 4:41 Entende-se, desse modo, que, para modificar esse tipo de dominação, não basta uma revolução econômica, é necessária uma revolução simbólica, que se processe nas cabeças. É preciso tomar consciência dos fatos para articular meios de revertê-los. É preciso reconhecer como é longo e difícil mudar. ${ }^{6,9}$ Nesse sentido, a escola pode ser percebida como a instituição mais significativa para gerar mudanças, inclusive no que se refere à reprodução da diferença de gênero. ${ }^{10}$ Certamente, as creches e pré-escolas constituem investimentos promissores para o desencadeamento desse processo de mudança; por meio delas, pode ser possível inculcar nas crianças habitus primários precursores da eqüidade e, possivelmente, de uma sociedade mais justa.

\section{RECURSOS METODOLÓGICOS}

Trata-se de um estudo exploratório-descritivo, de natureza qualitativa, cujo objetivo foi apreender, compreender e interpretar as percepções, apreciações e ações referentes à construção do feminino e masculino no processo de cuidar crianças em uma pré-escola da periferia do município do Rio Grande/RS.

Como local para realização do estudo escolheuse uma Instituição de Educação Infantil, que, desde 1997, mantém parceria com o Curso de Graduação em Enfermagem, da Fundação Universidade Federal 
do Rio Grande (FURG), para realização de atividades de ensino, pesquisa e extensão universitárias. Esta entidade filantrópica atende a aproximadamente cem crianças com idades entre três meses e seis anos, sendo o atendimento organizado de acordo com a faixa etária. Assim, na creche, são cuidadas crianças com idades entre três e quarenta e sete meses e, na pré-escola, crianças com idades entre quatro e seis anos. É importante salientar que há momentos, como os de atividades ao ar livre, na sala de vídeo e algumas festividades, em que crianças de diferentes faixas etárias compartilham o mesmo espaço físico.

Foram sujeitos do estudo três cuidadoras, identificadas por números de um a três, para garantir seu anonimato, e aproximadamente cinqüenta crianças que freqüentavam a pré-escola por ocasião da coleta de dados. O único critério para inclusão na amostra foi a concordância na assinatura do Termo de Consentimento Livre e Esclarecido por parte das cuidadoras e dos responsáveis legais pelas crianças.

Para a coleta de dados, empregaram-se as técnicas de observação e entrevista. A observação foi efetuada junto às cuidadoras e crianças da pré-escola, ou seja, com crianças de quatro a seis anos de idade, pois se acreditou que, em crianças dessa faixa etária, a apreensão das ações, apreciações e percepções acerca da construção do feminino e masculino ocorresse com maior facilidade. Em decorrência de seu estágio de desenvolvimento, tais crianças utilizam com maior desenvoltura a linguagem verbal, exteriorizam com maior clareza suas emoções e reproduzem de forma mais evidente o que lhes é ensinado. Dessa forma, a operacionalização dessa etapa serviu, inclusive, para aprimorar a capacidade de observação das pesquisadoras para futura coleta de dados junto às cuidadoras e crianças de menor idade em creches.

$\mathrm{Na}$ técnica de observação, optou-se pela Amostragem de Evento. Por meio deste método, a unidade de medida é o próprio comportamento observado, independentemente do tempo gasto para sua realização. Como vantagens dessa modalidade de coleta de dados, tem-se que ele: "preserva o contexto no qual o comportamento ocorre, tornando possível analisar relações causais; estrutura o campo da observação em unidades naturais de comportamentos, não sendo estes interrompidos com base em critérios de tempo; e reduz o tempo gasto na coleta de dados, embora esta seja uma vantagem comum a todas as técnicas de amostragem". 11:40
A observação foi efetuada em situações pré-definidas como durante a refeição, o banho, a escovação de dentes e atividades lúdicas, entre outras que ocorreram no cotidiano interacional de crianças e cuidadoras na instituição. O registro das observações foi efetuado por meio da elaboração de um diário de campo, ao final de cada turno de trabalho.

A realização das entrevistas apenas com as cuidadoras decorreu da constatação de que são elas as agentes sociais que mais interagem com as crianças e, presumivelmente, exercem maior influência na formação de habitus. Como roteiro utilizaram-se questões semi-estruturadas, previamente testadas. As entrevistas foram gravadas e transcritas na íntegra.

O projeto foi aprovado pelo Comitê de Ética em Pesquisa da FURG, garantindo-se, dessa, forma, que foram seguidas as diretrizes e normas regulamentadoras estabelecidas pela Resolução 196/ 96 do Conselho Nacional de Saúde (CNS). ${ }^{12}$ Os esclarecimentos que antecederam a assinatura do Termo de Consentimento Livre e Esclarecido, constantes na referida resolução, foram efetuados pela docente responsável pela pesquisa e pela bolsista CNPq, em contato direto com a presidente da instituição, as cuidadoras, pais, mães ou outros(as) responsáveis legais pelas crianças.

$\mathrm{Na}$ análise dos dados, adotou-se a hermenêuticadialética como referencial metodológico para delinear o caminho de pensamento construído a partir das etapas de ordenação dos dados, classificação dos dados e análise final. A análise de conteúdo foi a técnica analítica escolhida, ressaltando a necessidade de "se submeter essa técnica a uma superação dialética, isto é, ao conjunto de relações envolvidas". ${ }^{13: 40}$

\section{RESULTADOS E DISCUSSÕES}

Apreendeu-se que as cuidadoras, aparentemente, atuam de forma similar com meninos e meninas. Assim, nos diferentes contextos, ou seja, durante as refeições, atividades de higiene, atividades didáticopedagógicas em sala de aula ou no pátio, atuam tanto de forma solícita, atenciosa e carinhosa, quanto com energia e autoridade, visando a restringir comportamentos indesejáveis.

No entanto, quando submetidas a um olhar mais atento, ou inquiridas sobre o processo de cuidar meninos e meninas, expressam que há significativas diferenças. Entre as justificativas para tais diferenças demonstram a convicção de que meninos e meninas são 
biologicamente diferentes. Tal concepção é inquestionável, porém o curioso é que, para se referirem ao aspecto biológico, apresentam atributos socialmente construídos confirmando, assim, que "imbricadas às diferenças biológicas existentes entre homens e mulheres estão outras social e culturalmente construídas". ${ }^{14}$

Não vou dizer que o homem e a mulher são iguais e que dependendo da formação que eles tiverem em casa ou na escola isso vai se tornar igual. Não, não vai porque biologicamente eles são diferentes. Os meninos são mais agitados que as meninas, são menos tolerantes que as meninas. As meninas compreendem mais quando tu explica as coisas, os meninos não né, tem que falar mais de uma vez. porque eles querem usar a força (cuidadora 1).

A menina é mais meiga, o menino mais eufórico... sei lá como é que eu vou dizer... o menino é mais agressivo as vezes num certo ponto ele é estúpido no brincar com os outros... a menina é mais meiga e carinhosa no brincar (cuidadora 2).

Uma das cuidadoras deu indícios de que a distinção entre o feminino e o masculino não é tão polarizada quanto parece e se referiu à existência de exceções à regra ao dizer: tem diferença, mas existe meninas sapecas que gostam de brincar de jogar bola e de carrinho e tem meninos que são mais quietos, mais calmos que outros (cuidadora 3).

Essa mesma cuidadora, quando questionada acerca de sua conduta frente às brincadeiras e atitudes de meninos e meninas, demonstra sua estranheza quando tais atitudes fogem ao padrão considerado normal e fornece subsídios para que se perceba a forma como a escola pratica a pedagogia da sexualidade, ou seja, o disciplinamento dos corpos. ${ }^{3: 17}$ Relatando situações do dia-a-dia, a cuidadora consegue evidenciar sua ativa intervenção na construção da identidade de gênero.

Têm umas guriazinhas que pedem: "tia deixa eu jogar bola, deixa..." Eu digo não, vamos brincar de boneca e eu pego, sento no chão com elas e tento fazer elas brincarem de boneca e de casinha. É difícil, vem de casa, não adianta. Até no cruzar as pernas, tem uma guriazinha que cruza como homem e eu vou, e digo: não, não cruza assim, tu tem que cruzar desse jeito ó [...] (cuidadora 3).

Essas são, sem dúvidas, formas de inculcar nas crianças o padrão de comportamento "considerado culturalmente correto", ou seja, de inculcar-lhes um jeito de ser masculino e um jeito de ser feminino.

Num sentido mais amplo, pode-se dizer que o mundo social constrói os corpos por meio de um trabalho permanente de inculcação e nele imprime um programa de percepções, de apreciações e de ações. Nesse processo, as diferenças socialmente construídas acabam sendo consideradas naturais e, como tal, ins- critas no biológico e legitimadoras de uma relação de dominação. 2,4 Assim, "todo movimento corporal é distinto para os dois sexos: o andar balançando os quadris é assumido como feminino, enquanto dos homens espera-se um caminhar mais firme (palavra que no dicionário vem associada a seguro, ereto, resoluto - expressões muito masculinas e positivas), o uso das mãos [...], o posicionamento das pernas ao sentar, enfim, muitas posturas e movimentos são marcados, programados, para um e para outro sexo". ${ }^{15: 58-9}$

Interpretação semelhante pôde ser efetuada quando se analisaram as ações das cuidadoras. Foramlhes apresentadas as seguintes situações problema: a) um menino observa atentamente uma menina brincando com um carrinho, manifesta vontade de brincar, pedindo-lhe o brinquedo. O que você faria? Eu pegaria, acharia outro brinquedo que entretesse a menina pra dar o carrinho para o menino. Eu pegaria uma boneca ou ia procurar alguma coisa que influenciasse a menina a brincar de boneca e devolveria o carrinho pro menino (cuidadora 2).

Uma das cuidadoras, para justificar sua conduta, menciona a preocupação com os valores, saberes, significados e crenças da família das crianças, bem como em relação à postura da direção da instituição, pois se trata de funcionária nova. Ah... eu vou dizer para a menina dar o carrinho pra ele. Primeiro porque é complicado, assim ó [...] a gente não sabe como é a família [...] eu particularmente vim pra cá esse ano e eu não sei como a família trabalha isso. Então pra explica pra ele que uma menina também pode brincar de carrinho de repente eu vou ter confrontamento com a família en entregaria o carrinho para ele (cuidadora 1).

Quando lhe foi apresentada a situação inversa, ela mantém seu padrão de resposta: b) uma menina observa atentamente um menino brincando com uma boneca, manifesta vontade de brincar, pedindo-lhe o brinquedo. O que você faria? Eu faria a mesma coisa, entregaria a boneca para a menina (cuidadora 1).

Nesse caso, fica evidente o reconhecimento de que estruturas como a família e a escola constituem autoridades na manutenção das identidades de gênero. A cuidadora não faz distinção na conduta adotada frente a meninos ou meninas, porém segue a ordem natural dos acontecimentos e age de acordo com a norma tacitamente estabelecida.

Com referência ainda às situações-problema apresentadas, outra cuidadora menciona: eu conversaria e tentaria trocar os brinquedos. Se ela me pedisse para brincar com a boneca que está com o menino eu tentaria trocar os brinquedos... daria um carrinho para o menino e a boneca para a menina (cuidadora 3). 
Tal padrão de comportamento está internalizado na cuidadora sob forma de habitus e, por não gerar conflito passa despercebido. É com a repetição dessas condutas que a escola, no caso a pré-escola, contribui, ao longo do processo de escolarização, para a interiorização, nas crianças da ordem social estabelecida, por meio da qual se aprende a ser homem e a ser mulher.

Das seções observacionais, apreendeu-se que há consonância entre as percepções e apreciações das cuidadoras com suas ações, ou seja, tanto no agir quanto ao emitir suas opiniões, elas expressam a interiorização sociocultural do feminino e do masculino. Selecionaram-se algumas situações que ilustram as diferentes formas de cuidar meninos e meninas. Aos meninos, são permitidas brincadeiras mais arriscadas, inovadoras, espetaculares enquanto que as meninas, frágeis e delicadas, devem seguir a norma do jogo.

Em uma brincadeira no escorregador, em que participavam meninos e meninas, sob supervisão de uma cuidadora, o menino escorregou de ponta-cabeça sem receber nenhum tipo de advertência. A menina, ao tentar adotar a mesma posição para escorregar, foi advertida quanto ao perigo e recebeu a indicação de que é sentada que se escorrega.

Uma menina e um menino brincam em balanços. Parece que vai iniciar uma competição na qual ganha quem balançar mais alto. A cuidadora imediatamente repreende a menina solicitando que diminua a velocidade, pois é perigoso. Esta obedece sem questionar. O menino segue acelerando o brinquedo, sem que a cuidadora lhe chame a atenção.

Assim, o brincar inocente passa a ser vigiado pelas normas sociais, conduzindo as crianças a apresentarem um comportamento tido como adequado ao seu próprio sexo. A observação da norma acaba, muitas vezes, gerando nas meninas insegurança e fragilidade. "A insegurança provoca medo, aumenta a tendência, a conduta defensiva, dificulta a disposição de assumir os riscos inerentes a qualquer tipo de iniciativa pessoal, leva a padrões de relacionamento dependentes, etc". 16:51

Houve situações em que a dominação dos meninos foi facilmente evidenciada, porém, quando as meninas se submeteram, aceitando sem reclamações, a situação foi encarada como natural, pelas cuidadoras.

Uma menina aproxima-se de um grupo de meninos que brincam de carrinho na areia. O menino, sem justificar o porquê, diz que ela não pode brincar. Menina permanece alguns instantes em pé, observan- do e aos poucos, em silêncio, sem expressar qualquer reação, vai se afastando. Cuidadora presencia, porém não interfere.

Observou-se que as cuidadoras apenas interferem nas interações de meninos e meninas quando tais situações são geradoras de conflito ou choro. Nestas, solicitam aos meninos que tenham modos e consolam as meninas, reforçando a noção da fragilidade feminina. Nas situações observadas prevaleceu a vontade dos meninos que, mesmo inconscientemente foram incentivados em sua agressividade, ousadia e competitividade.

Menina brinca com um telefone. Menino agressivamente tira-lhe o brinquedo das mãos. Cuidadora repreende o menino, porém não pede que devolva o brinquedo. Menina chora e, carinhosamente, é consolada, no colo da cuidadora.

Menina encontra-se no pátio brincando de carrinho. Menino chega e, usando força, pega o carrinho da mão da menina. Pega, ainda, uma caixa de brinquedos que estava com a menina. Cuidadora observa e pede para o menino ter modos. Ele não devolve o carrinho nem a caixa. Menina aceita passivamente.

Foi possível apreender ainda que, desde os primeiros anos de vida, as crianças já têm interiorizado um padrão de comportamento para meninas e para meninos, tendo, pela própria pressão do grupo, dificuldade de transgredi-lo.

Um menino referiu estar fazendo um bolo de chocolate. $\mathrm{O}$ amigo rindo perguntou: tu faz bolo? $\mathrm{O}$ primeiro corrigiu respondendo: não é bolo, é uma moto. $\mathrm{O}$ amigo não se convenceu com a nova afirmação e zombateiramente falou: mulherinha!!

$\mathrm{Na}$ fila do banheiro uma menina passa para a fila dos meninos que em coro dizem: homenzinha! A cuidadora, irritada com o barulho, pede para que ela retorne à fila feminina.

Assim, as oportunidades para questionar, junto às crianças que freqüentam a pré-escola, os padrões preestabelecidos de masculinidade e feminilidade, vão naturalmente sendo perdidas, e a reprodução das diferenças vai sendo incorporada desde as primeiras etapas do processo educacional. Como agravante constatou-se que as cuidadoras também expressam sua percepção estereotipada ao interagir com as crianças.

Meninas encontram um sapato feminino entre os brinquedos e começam a brincar. Um menino aproxima-se e calça o sapato sendo chamado de "bitoca"* pela cuidadora. Menino sorri e imediatamente tira o 
sapato. Cuidadora comenta: ainda bem que teus colegas não enxergaram.

Evidenciou-se, assim, que tanto as cuidadoras quanto as próprias crianças têm incorporado habitus que indicam a polarização dos comportamentos femininos e masculinos, e que qualquer tentativa de transgressão, ou seja, de ruptura com o culturalmente aceitável é imediatamente censurada. Essas são apenas algumas das estratégias que garantem, mesmo que de forma inconsciente, a incorporação de estereótipos de gênero em crianças desde a mais tenra idade.

\section{CONSIDERAÇÕES FINAIS}

É inquestionável que o processo de cuidar crianças em pré-escolas vem contribuindo significativamente na reprodução da ordem dos gêneros. Por meio dele, cuidadoras e demais agentes sociais integrantes das equipes multiprofissionais vêm incutindo nas crianças suas próprias percepções e apreciações acerca da feminilidade e masculinidade. Essas marcas da cultura, inculcadas ao longo da trajetória de vida de cada pessoa, permeiam, de forma naturalizada, suas ações e se reproduzem naturalmente. Durante as brincadeiras, no horário das refeições, higiene, sono ou ainda nas atividades pedagógicas, as crianças, em meio a carinhos, aconchegos, reforços ou repreensões, vão distinguindo e interiorizando o que culturalmente se espera das meninas e o que se espera dos meninos.

$\mathrm{Na}$ realidade, no que se refere ao cuidado infantil, nenhuma apreciação ou ação pode ser considerada neutra. Assim, torna-se necessária uma adequada capacitação das equipes que atuam em instituições infantis para que o choque da imposição cultural seja evitado.

$\mathrm{Na}$ tentativa de reorganização dos modos de cuidar crianças em instituição de educação infantil, é necessário que os valores, saberes e crenças de cada família sejam respeitados tanto quanto os das cuidadoras. Assim, é preciso ter em mente que nenhuma atitude de censura, julgamento ou repreensão poderá auxiliar na desnaturalização das diferenças do cuidar meninos e meninas. Sua efetivação requer a coparticipação da comunidade institucional, com ênfase na interação de enfermeiras, cuidadoras e familiares, numa atitude de reflexão acerca das certezas, das ações naturais e impensadas, da divisão sexual das brincadeiras, das filas, dos espaços externos e internos, dos direitos e deveres de meninas e meninos. Requer ainda um questionamento, acerca da enormidade de circunstâncias tão corriqueiras e naturais, que culturalmente incorporadas, passam despercebidas, porém, afetam a saúde individual e coletiva. Para modificar essa modalidade de cuidar, é, pois, necessário tomar consciência dos fatos e encontrar estratégias para revertê-los, bem como é essencial ter a convicção de que "o desafio para os próximos anos será ativar o potencial para a promoção da saúde inerente em muitos setores da sociedade, nas comunidades e nas famílias". 17:416 Acredita-se que a Enfermagem, engajada no processo de cuidar crianças em pré-escolas, possa contribuir significativamente para o desencadeamento de novos e precursores habitus; neste caso, de eqüidade de gênero.

\section{REFERÊNCIAS}

1 Comitê de Desenvolvimento Integral da Primeira Infância (CODIPI). Projeto "Começando melhor". Brasília: Comunidade Solidária; 2001.

2 Bourdieu P. Trabalhos e Projetos. In: Ortiz R, organizador. Pierre Bourdieu: sociologia. São Paulo: Ática; 1994. p.3845.

3 Louro GL. O corpo educado: pedagogias da sexualidade. 2a ed. Belo Horizonte: Autêntica; 2001.

4 Bourdieu P. A dominação masculina. Rio de Janeiro: Bertrand Brasil; 1999.

5 Louro GL. Gênero, sexualidade e educação: uma perspectiva pós-estruturalista. 2a ed. Petrópolis: Vozes; 1998.

6 Bourdieu P. Pierre Bourdieu entrevistado por Maria Andréa Loyola. Rio de Janeiro: EdUERJ; 2002.

7 Scott J. Gênero: uma categoria útil de análise histórica. Educação e Realidade. 1990 Jul-Dez.; 16(2):5-22.

8 Saffioti HIB. Posfácio: conceituando o gênero. In: Saffioti HIB, Muñoz-Vargas M, organizadores. Mulher brasileira é assim. Rio de Janeiro/Brasília: Rosa dos Tempos/ NIPAS/UNIVEF; 1994. p.271-83.

9 Bourdieu P. Novas reflexões sobre a dominação masculina. In: Lopes MJM, Meyer DE, Waldow VR. Gênero e saúde. Porto Alegre: Artes Médicas; 1996. p.28-40.

10 Bourdieu P. Razões práticas: sobre a teoria da ação. Campinas: Papirus; 1997.

11 Conselho Nacional de Saúde (BR), Conselho Nacional de Ética em Pesquisa em Seres Humanos. Resolução No 196 de 10 de outubro de 1996: diretrizes e normas regulamentadoras de pesquisas envolvendo seres humanos. Brasília (BR): O Conselho; 1997.

12 Dessen MA, Borges LM. Estratégias de observação do comportamento em psicologia do desenvolvimento. In:

* Termo utilizado para referir-se a efeminado, homossexual.

Texto Contexto Enferm, Florianópolis, 2006; 15(1): 35-42. 
Romanelli G, Biasoli-Alves ZM. Diálogos metodológicos sobre prática de pesquisa. Ribeirão Preto: Legis Summa; 1998.

13 Minayo MCS. O desafio do conhecimento: pesquisa qualitativa em saúde. 6a ed. São Paulo/Rio de Janeiro: Hucitec/Abrasco; 1999.

14 Scott J. Gênero: uma categoria útil de análise histórica. Educação e Realidade. 1995 Jul-Dez; 20(2):71-99.
15 Louro GL. Uma leitura da história da educação sob a perspectiva de gênero. Teoria e Educação. 1992 Jul-Dez; 6(2):53-67.

16 Zabalza MA. Qualidade em educação infantil. Porto Alegre: Artes Médicas; 1998.

17 Meirelles BHS, Erdmann AL. A interdisciplinaridade como construção do conhecimento em saúde e enfermagem. Texto Contexto Enferm. 2005 Jul-Set; 14(3): 411-8. 